\title{
Limites e possibilidades no desenvolvimento de estratégias de Turismo de Base Comunitária em um território quilombola
}

\author{
Limits and possibilities in the development of Community-Based Tourism \\ strategies in quilombola territory

\section{Límites y posibilidades en el desarrollo de estrategias de Turismo de Base Comunitaria en un territorio quilombola}

\author{
Dyego de Oliveira Arruda ${ }^{1}$ \\ Juliano Pessanha Gonçalves ${ }^{1}$
}

Recebido em 07/05/2018; revisado e aprovado em 19/06/2018; aceito em: 28/06/2018.

DOI: http://dx.doi.org/10.20435/inter.v21i1.1968

\begin{abstract}
Resumo: O presente artigo tem como objetivo geral compreender os limites e as possibilidades da difusão de iniciativas de turismo de base comunitária no território quilombola de São José da Serra, no sul do Estado do Rio de Janeiro. Com base em uma pesquisa de abordagem etnometodológica, em que foi possível conhecer os ritos, cerimônias, produtos típicos, modos de vida e crenças do povo de São José da Serra, constatou-se que fatores exógenos e endógenos constituem empecilhos para a difusão do turismo comunitário no território, ao passo que a riqueza cultural e a beleza cênica do lugar são trunfos para o desenvolvimento do turismo comunitário em São José da Serra.
\end{abstract}

Palavras-chave: turismo; comunidades tradicionais; etnometodologia.

Abstract: This article aims to understand the limits and possibilities of the diffusion of community-based tourism initiatives in the quilombola territory of São José da Serra, in the south of the State of Rio de Janeiro, Brazil. Based on an ethnomethodological research, in which it was possible to know the rites, ceremonies, typical products, ways of life and beliefs of the people of São José da Serra, we found that exogenous and endogenous factors are obstacles to the diffusion of community tourism in the territory, while the cultural richness and scenic beauty of the place are possibilities for the development of community tourism in São José da Serra.

Keywords: tourism; traditional communities; ethnomethodology.

Resumen: El presente artículo tiene como objetivo comprender los límites y las posibilidades de la difusión de iniciativas de turismo de base comunitaria en el territorio quilombola de São José da Serra, en el sur del Estado de Rio de Janeiro, Brasil. Con base en una investigación de abordaje etnometodológico, en que fue posible conocer los ritos, ceremonias, productos típicos, modos de vida y creencias del pueblo de São José da Serra, comprobamos que factores exógenos y endógenos constituyen dificultades para la difusión del turismo comunitario en el territorio, mientras que la riqueza cultural y la belleza escénica del lugar son posibilidades para el desarrollo del turismo comunitario en São José da Serra.

Palabras clave: turismo; comunidades tradicionales; etnometodologia.

\section{INTRODUÇÃO}

Quais as dinâmicas a partir das quais se podem programar iniciativas de Turismo de Base Comunitária (TBC) em um território tradicionalmente ocupado por comunidades quilombolas? Quais as limitações e os trunfos que uma comunidade quilombola pode possuir, no âmbito da difusão e do fortalecimento de estratégias de turismo comunitário?

Tendo como base as supracitadas problemáticas de pesquisa, o presente artigo tem como objetivo geral compreender, em uma perspectiva exploratória e qualitativa, os limites e as possibilidades da difusão de iniciativas de turismo de base comunitária no território do quilombo

\footnotetext{
${ }^{1}$ Centro Federal de Educação Tecnológica Celso Suckow da Fonseca (Cefet/RJ), Campus Maracanã, Rio de Janeiro, Rio de Janeiro, Brasil.
} 
São José da Serra, localizado na área rural do distrito de Santa Isabel do Rio Preto, na cidade de Valença, interior do estado do Rio de Janeiro.

Embasado no empoderamento e na tomada de iniciativa dos próprios atores do território, em um processo de cunho endógeno, o turismo de base comunitária contrasta à lógica homogeneizante e massificada do turismo convencional, conclamando os visitantes a experimentarem detalhes do modo de vida tradicional das comunidades receptoras, entrando em contato com as especificidades da culinária local, além dos costumes, crenças, hábitos e rotinas dos territórios submetidos a essa nova forma de "fazer turismo" (MANO; MAYER; FRATUCCI, 2017; FABRINO; NASCIMENTO; COSTA, 2016).

Parte-se da perspectiva de que o turismo comunitário, na medida em que é empreendido pelas próprias comunidades, pode ser um mecanismo para: (a) promover e/ou catalisar o desenvolvimento local endógeno dos territórios (CORIOLANO; VASCONCELOS, 2013); (b) contribuir com a conservação do meio ambiente (GRIMM; SAMPAIO, 2016); (c) estimular ações de cunho colaborativo e solidário, não raro nos moldes da economia solidária (ARRUDA; MARIANI; FISCHER, 2013); (d) proporcionar uma verdadeira transformação dos turistas, que conseguem conhecer melhor a si próprios na medida em que entram em contato com as particularidades "do outro", na sua essência mais autêntica (ZAOUAL, 2008) e; (e) gerar renda e ocupação às comunidades tradicionais, ao mesmo tempo que auxilia na manutenção das especificidades socioculturais dessas comunidades (IRVING, 2009).

De todo modo, para que as estratégias de turismo de base comunitária obtenham êxito, é indispensável que os agentes que tradicionalmente ocupam o território (tais como pequenos empreendedores, associações, poder público, além das próprias pessoas, de um modo geral) atuem de modo coordenado e solidário, tendo como propósito formatar produtos turísticos que, além de serem autênticos e transformadores, também proporcionem benefícios duradouros às comunidades locais (BURGOS; MERTENS, 2016; TOLKACH; KING, 2015).

Existe uma tradição de pesquisas e reflexões, no Brasil, que focalizam a temática do turismo comunitário em: (a) territórios rurais (GUZATTI; SAMPAIO; CORIOLANO, 2013); (b) áreas costeiras e praias (BURGOS; MERTENS, 2015); (c) áreas de assentamento e reforma agrária (LACERDA et al., 2007); e (d) comunidades tradicionais, tais como territórios tradicionalmente habitados por grupos indígenas e comunidades quilombolas (LUSTOSA; ALMEIDA, 2011; SILVA, 2014; SILVA; MATTA; SÁ, 2016). No Brasil, há um grupo de pesquisadores que se reúne regularmente no Encontro Nacional de Turismo de Base Local (ENTBL), que, desde 1997, conclama a comunidade científica e demais interessados a refletirem em torno dos benefícios e ônus das estratégias de turismo comunitário.

Silva (2014), assim como Silva, Matta e Sá (2016), pondera que o turismo comunitário empreendido em áreas quilombolas, além de proporcionar geração de ocupação e renda às comunidades receptoras, também tem como perspectiva a valorização das raízes e da influência da população negra na constituição das sociedades contemporâneas, permitindo uma verdadeira transformação nos visitantes, que se veem diante de uma cultura e modo de vida peculiares, tão importantes na gênese da sociedade brasileira.

No território de São José da Serra, foco da presente investigação, constata-se a presença de uma comunidade de resistência, que abrigou negros e negras que possuíam elementos identitários comuns entre si e que lutaram para o reconhecimento de sua cultura, crenças e modos de vida. Atualmente, por intermédio do jongo (uma dança típica, ritmada pelo som de 
tambores feitos de cascas ocas de árvores e peles de animais), da religiosidade e das histórias e mitos em torno de uma lendária e frondosa árvore de jequitibá, essa comunidade preserva as suas heranças culturais seculares (SILVA, 2016).

Portanto, rememorando as histórias, mitos, modos de vida e de organização da comunidade quilombola de São José da Serra, o presente artigo, ao discutir os limites e as possibilidades das estratégias de turismo comunitário neste território, subdivide-se em cinco partes, além desta introdução: na primeira parte, há uma discussão teórico-conceitual acerca do turismo de base comunitária; na segunda parte, apresentam-se os aspectos metodológicos que subsidiaram a etapa empírica da presente investigação; na terceira parte, consta um breve relato histórico acerca da origem e do modo de organização do quilombo São José da Serra, ao passo que na quarta parte há uma discussão sobre os trunfos e as limitações das potenciais estratégias de turismo de base comunitária neste território; por fim, na quinta e última parte, verificam-se as principais inferências e considerações finais do artigo, com a consequente indicação de particularidades que podem subsidiar políticas públicas e ações coletivas em torno do fomento ao turismo comunitário em territórios quilombolas.

\section{TURISMO DE BASE COMUNITÁRIA: ALGUNS ASPECTOS BASILARES}

O turismo de base comunitária representa uma modalidade de turismo que normalmente é desenvolvida em pequena escala, tendo como perspectiva a manutenção das características socioculturais das comunidades receptoras, ao mesmo tempo que se geram renda e ocupação nos territórios (TOLKACH; KING, 2015; ARAÚJO; GELBCKE, 2008).

Pode-se considerar que a própria cultura, a culinária típica, os modos de vida e de preparo de bens e serviços artesanais, além dos recursos ambientais do território, correspondem, conjuntamente, aos grandes ativos para a difusão das iniciativas de turismo de base comunitária (SALAZAR, 2012).

Ao embasar-se no empoderamento e na capacidade de iniciativa dos habitantes de um determinado território, entende-se que o turismo comunitário permite o atendimento às necessidades comunitárias e do próprio indivíduo, em muitos casos a partir da criação e do aprimoramento de instituições locais que vão zelar pela cultura, manutenção dos modos de vida típicos, conservação do meio ambiente, além da melhoria da infraestrutura local (LIMA, 2011).

O Ministério do Turismo (MTur), ao elaborar um manual com direcionamentos para a formulação de políticas públicas de fomento ao turismo de base comunitária, reconhece que tal construto teórico é deveras contemporâneo e multidisciplinar, sendo, portanto, um exercício difícil conceituá-lo de modo contundente e unânime. De todo modo, o MTur pondera que as definições mais usuais sobre turismo de base comunitária trazem alguns princípios basilares, quais sejam (BRASIL, 2010, p. 16): (a) autogestão; (b) associativismo e cooperativismo; (c) democratização de oportunidades e benefícios; (d) centralidade da colaboração, parceria e participação; (e) valorização da cultura local; e (f) protagonismo das comunidades locais na gestão da atividade e/ ou na oferta de bens e serviços turísticos, visando à apropriação, por parte destas comunidades, dos benefícios advindos do desenvolvimento da atividade turística.

Fabrino, Nascimento e Costa (2016, p. 176), por seu turno, após uma extensa revisão de literatura, ponderam que o turismo de base comunitária é caracterizado pelos seguintes elementos: (a) dominialidade (magnitude em que a própria comunidade controla as propriedades 
e faz a gestão dos produtos turísticos); (b) organização comunitária; (c) democratização de oportunidades e repartição de benefícios; (d) integração econômica (relação do turismo comunitário com outras atividades econômicas existentes no território); (e) interculturalidade (magnitude do intercâmbio cultural entre os visitantes e a comunidade local); e (f) qualidade ambiental (alusiva às formas de manejo e conservação dos ativos naturais existentes no território). Os mesmos autores supracitados, após uma investigação empírica de experiências de turismo comunitário no Ceará, concluem que os elementos "dominialidade" e "organização comunitária" são centrais, de tal modo que os elementos restantes podem ser compreendidos como consequências das práticas efetivas de turismo de base comunitária no território.

Percebe-se que o turismo comunitário representa uma modalidade de turismo que é transversal a outras tipologias de turismo existentes, tais como o turismo rural, ecoturismo, turismo de aventura, turismo gastronômico e afins (SANCHO; MALTA, 2015). Independentemente do "substrato" no qual a prática turística ocorra (quer seja no meio rural ou em áreas naturais, por exemplo), deve-se pontuar que o elemento caracterizador do turismo comunitário é justamente a participação efetiva de grupos e comunidades tradicionais, que, embasados em sua cultura, hábitos e modo de vida típicos, formatam, colaborativamente, produtos turísticos autênticos (NUNES; MENEZES, 2017).

Outro aspecto caracterizador do turismo de base comunitária é o fato de tal atividade ser efetivamente situada, ou seja: o que a motiva é a particularidade de estar circunscrita a um território específico, com toda a carga emocional e simbólica inerente a este território (ZAOUAL, 2008; BARTHOLO, 2009). Os turistas, cada vez mais ávidos pela busca de experiências memoráveis, motivam-se em deslocar-se até os "sítios específicos" (mesmo estando longe dos grandes centros urbanos, não raro em locais de difícil acesso), em função do interesse em integrar-se efetivamente, mesmo que por curto intervalo de tempo, a uma dinâmica de vida típica e, portanto, autêntica e singular.

Nesse ínterim, considera-se que a difusão e consolidação das estratégias de turismo comunitário, contemporaneamente, dá-se muitas vezes em uma contraposição à lógica do turismo de massa, pós-industrial, que preconiza uma verdadeira padronização dos destinos turísticos (ZAOUAL, 2008; BURGOS; MERTENS, 2016).

Zaoual (2008) pondera que o turismo de massa apresenta em seu bojo elementos que provocarão a sua própria derrocada, uma vez que os destinos turísticos pós-industriais cada vez mais mostram-se degradados, despersonalizados, sem o mínimo de respeito à sua capacidade de carga, em muitos casos diferenciando-se pouco em relação aos locais de residência habitual dos turistas. Sendo assim, segundo o supracitado autor, abre-se espaço às ações e estratégias de turismo comunitário, mais autênticas, colaborativas, que conservam as especificidades eco-socioculturais dos territórios, ao mesmo tempo que também permitem que o turista possa transformar a si próprio diante do contato com o outro, numa lógica calcada na alteridade.

De todo modo, não é uma tarefa fácil planejar e gerir estratégias de turismo de base comunitária. Mielke e Pegas (2013) salientam que são recorrentes os casos de insucesso das iniciativas de turismo comunitário, tanto no Brasil como em outros países. Em suma, os principais aspectos que determinam o fracasso das ações de turismo de base comunitária são os seguintes (MIELKE; PEGAS, 2013):

Dificuldades de acesso ao mercado: os produtos turísticos muitas vezes possuem baixa qualidade (o que não desperta o interesse de determinados segmentos de turistas). Além disso, 
muitas comunidades que implementam estratégias de turismo comunitário não estabelecem relações comerciais com agentes intermediários do turismo (tais como operadoras e agências de turismo), dificultando a comercialização do produto turístico. Destaque-se ainda que muitos dos destinos de turismo de base comunitária localizam-se em áreas de difícil acesso, com precária infraestrutura de transportes, o que acaba contribuindo também para que um menor contingente de turistas se interesse por conhecer esses territórios.

Problemas de governança interna: muitas comunidades que desenvolvem estratégias de turismo comunitário não conhecem, plenamente, as potencialidades e os desafios inerentes à presença da atividade turística nos territórios em que residem. Além disso, são comuns os casos em que o turismo comunitário não é realizado por intermédio de ações coletivas (tais como associações e/ou empresas de base comunitária e solidária), dificultando a sustentabilidade dessas iniciativas e impedindo que o turismo seja, de fato, uma atividade que gere benefícios duradouros às comunidades.

Dificuldades na gestão de parcerias estratégicas de interesse: muitas comunidades que empreendem ações de turismo comunitário demonstram empecilhos para se inserirem em roteiros turísticos, estabelecendo relações comerciais e parcerias estratégicas com agentes econômicos eventualmente já consolidados no trade turístico (tais como rede de hotéis, empresas de transporte, além das próprias operadoras e agências de turismo). Ademais, ressalte-se a dificuldade de as comunidades acessarem recursos de políticas públicas de fomento ao turismo.

No caso de comunidades que se valem do turismo comunitário como fonte de geração de renda, ocupação, manutenção da biodiversidade e preservação da cultura, a atividade turística já surge no território cercada de muitas expectativas, que podem não se materializar por completo no curto prazo, implicando em desmobilização e frustração por parte da comunidade, "matando" as ações de turismo comunitário que, com um pouco mais de planejamento e gestão, talvez fossem exitosas no médio e longo prazos (MIELKE, 2010).

\section{ASPECTOS METODOLÓGICOS DO ESTUDO}

O presente artigo teve como base uma abordagem qualitativa e exploratória, sendo realizado um estudo de caráter etnometodológico, no qual os pesquisadores estabeleceram contatos regulares e sistemáticos com a comunidade de São José da Serra, com o propósito de desvendar as principais histórias, sentidos, significados e tradições partilhados pelos membros da comunidade sob análise.

Em síntese, vale destacar que a abordagem qualitativa conferida ao estudo se deveu em função da própria natureza do problema de pesquisa, que exigiu métodos mais indiretos e interpretativos para que se pudessem compreender, em profundidade e com riqueza de detalhes, os limites e as possibilidades para a eventual difusão de estratégias de turismo comunitário no território do quilombo de São José da Serra (GODOY, 1995; MAXWELL, 2012).

A abordagem exploratória do estudo, por seu turno, justificou-se pelo caráter emergente do problema de pesquisa, que se deteve nas dinâmicas das possibilidades do turismo em uma comunidade cuja posse definitiva do território só ocorreu ao longo do ano de 2015 - portanto há muito pouco tempo. Assim sendo, estudos exploratórios podem auxiliar em um refinamento maior de problemas de pesquisa para investigações mais específicas e pontuais no território-alvo da presente análise (MAXWELL, 2012). 
Por fim, destaque-se que o caráter etnometodológico do estudo permitiu que os pesquisadores compreendessem, a partir de observações participantes, dos relatos orais e das interações sociais estabelecidas com os membros da comunidade, o modo como são atribuídos significados às coisas, fenômenos e situações intrínsecas à própria dinâmica comunitária (BISPO; GODOY, 2012).

Considera-se que a etnometodologia, cujos princípios epistemológicos remetem a Garfinkel (1967), perfaz uma abordagem metodológica que se detém nas atividades práticas empreendidas pelos atores sociais, os quais, uma vez estabelecendo interações entre si, produzem sentidos e significados à sua própria vida e ao contexto no qual estão inseridos.

Oliveira e Montenegro (2012) lembram que a etnometodologia representa uma abordagem epistemológica eminentemente prática e realística. Assim sendo, o foco da etnometodologia está no contato permanente com os atores sociais para, a partir dos instrumentos (métodos) que eles próprios usam no seu quotidiano, descrever em detalhes e de modo fidedigno uma determinada realidade social, sem nenhuma perspectiva apriorística de análise (MAYNARD; CLAYMAN, 1991).

A unidade analítica da etnometodologia, portanto, são os instrumentos a partir dos quais os atores sociais, interagindo entre si, atribuem significados às circunstâncias da vida (GARFINKEL, 1967; BISPO; GODOY, 2012). Como exemplos de instrumentos que permitem interações sociais e a consequente atribuição de significados pelos indivíduos, é possível citar: a linguagem, os símbolos, as formas de comportamento, além dos ritos e das cerimônias partilhados pelos atores sociais.

Em suma, as informações empíricas e reflexões que fundamentaram o presente artigo foram decorrentes de projetos de pesquisa e extensão desenvolvidos no território de São José da Serra ao longo dos anos de 2016 e 2017. De um modo geral, tais projetos, que tiveram como escopo a geração de produtos e serviços à comunidade quilombola sob análise, implicaram em visitas regulares ao território de São José da Serra e contaram com a colaboração de professores mestres e doutores (entre os quais, os autores do presente artigo), além de alunos de pós-graduação lato sensu, graduação e cursos técnicos, todos vinculados ao Centro Federal de Educação Tecnológica Celso Suckow da Fonseca (CEFET/RJ).

As atividades de pesquisa e, sobretudo, as ações de extensão que deram textura ao presente estudo permitiram a captação de uma amplitude de "olhares", não raro provenientes dos próprios alunos envolvidos no projeto e de membros da comunidade, desnudando indícios reveladores das potencialidades e dos desafios inerentes ao turismo de base comunitária em São José da Serra.

Assim, ao longo das visitas à comunidade sob análise, os pesquisadores tiveram a possibilidade de observar os seguintes elementos: (a) os ritos e as cerimônias culturais e religiosas da comunidade; (b) os produtos típicos da gastronomia local, representados pelas receitas típicas e pela preservação de variedades tradicionais de milho e feijão; (c) as festas e celebrações da comunidade (como as festas da cultura negra e da queima do balaio); (d) os lugares sagrados do quilombo, como a trilha que leva a um frondoso pé de jequitibá, por exemplo; e (e) a beleza cênica do território, margeado por montanhas e coberto por cachoeiras.

Deve-se salientar que os supracitados aspectos, no âmbito da etnometodologia, constituíram objetos de análise do presente estudo, permitindo uma reflexão em torno da gênese e das características da comunidade de São José da Serra e dos caminhos em que o turismo de base comunitária pode difundir-se no território.

Destaque-se que, após os trabalhos de campo que subsidiaram o presente estudo, os pesquisadores que coordenaram as ações de campo e que subscrevem o presente artigo pre- 
encheram diários de bordo, tendo como escopo o registro das principais histórias, curiosidades, vivências e particularidades do contato com o povo do território.

Os supracitados diários de bordo, somados a todas as percepções e experiências apreendidas em campo, foram submetidos a técnicas de análise de conteúdo, que tiveram como escopo permitir a realização de análises e inferências com base nos textos, discursos, observações e objetos captados e/ou observados ao longo das incursões no campo empírico da pesquisa (BARDIN, 2011). Os principais "produtos" decorrentes da análise de conteúdo feita no âmbito do presente artigo constam nos tópicos que seguem.

\section{BREVE HISTÓRICO DA COMUNIDADE DE SÃO JOSÉ DA SERRA}

O território da comunidade de São José da Serra atualmente abriga uma população permanente de cerca de 200 pessoas, distribuídas em torno de núcleos familiares esparsos geograficamente, por uma área de 476 hectares.

A renda da população de São José da Serra é proveniente de serviços, na sua maioria, esporádicos, prestados em fazendas da região, em atividades de cultivo em pequenas hortas comunitárias, bem como da comercialização de artesanato, de recursos provenientes de aposentadorias, de programas sociais (tais como o bolsa família) e ainda de uma parcela menos representativa de recursos provenientes de relações formais de emprego.

Quanto à geografia do território, destaca-se a topografia montanhosa - em razão da sua localização na Serra da Beleza² -, que limita a prática da agricultura a algumas poucas áreas. Nos espaços em que a prática agrícola é factível, predomina uma agricultura de base familiar e voltada à subsistência, caracterizada pela produção diversificada de variedades tradicionais de sementes de milho e feijão, destinadas ao abastecimento das famílias da comunidade.

Outra característica física importante é a presença de áreas de matas e florestas, além de recursos hídricos que abastecem pequenos riachos, cuja água é utilizada para o consumo doméstico, para a irrigação das lavouras e para o abastecimento de açudes. Tais especificidades evidenciam não somente uma composição paisagística relevante, do ponto de vista cênico, mas também fazem do território sob análise um importante provedor de serviços ambientais.

Feitas estas considerações iniciais, é importante registrar que a história da comunidade de São José da Serra ilustra, em boa medida, as dificuldades enfrentadas pelos negros na afirmação de suas identidades socioculturais. As condições sob as quais atualmente vivem os quilombolas do supracitado território evidenciam a dimensão dos obstáculos à sua inserção numa economia de mercado e ao seu reconhecimento como cidadãos portadores de direitos básicos, que lhes garantam um mínimo de cidadania. São escassas as políticas públicas que atingem a população de São José da Serra, o que reflete no precário acesso à educação e saúde públicas, sem contar os aspectos relacionados aos serviços básicos de infraestrutura, tais como saneamento, energia e transportes minimamente adequados.

Com a instrumentalização do artigo 68 da Constituição Federal, que prevê a propriedade definitiva, assegurada pelo Estado, das terras historicamente ocupadas pelos remanescentes das comunidades quilombolas, o povo de São José da Serra, sobretudo com a consolidação do papel político assumido pelo seu porta-voz e líder, Antônio Nascimento Fernandes, o Toninho,

\footnotetext{
2 "Serra da Beleza" é um nome popular da Serra da Taquara, uma região montanhosa localizada em Valença, RJ.
} 
intensifica a construção de uma identidade coletiva, afirmando-se portadora de atributos, principalmente culturais e históricos, que lhe conferem os traços característicos de uma comunidade quilombola (BRASIL, 1988). Ao mesmo tempo, dá-se início a uma estratégia que instaura um conflito fundiário legitimado pelo recurso à via judicial, conforme apontado por Mattos (2006), e que tem por fonte a própria vigência do dispositivo constitucional.

Foi só no correr do ano de 1998 que, por meio de um convênio entre o Instituto de Terras do Estado do Rio de Janeiro (ITERJ) e a Fundação Palmares, uma equipe de antropólogos e historiadores dirigiu-se até a comunidade, com o propósito de iniciar os procedimentos para a avaliação das condições e dos requisitos para reconhecimento da comunidade como remanescente de quilombo, nos termos previstos na Constituição Federal.

No ano de 1999, os proprietários da fazenda São José ingressaram, judicialmente, com uma ação de contestação do processo de reconhecimento. Teve início, portanto, uma longa espera pela resolução do conflito pela terra, na via judicial.

A mobilização da comunidade liderada por Toninho levou à criação de sua associação de moradores, registrada em junho de 2000, no Cartório do 1으 Ofício de Notas de Valença, RJ.

Percorrido um período de duas décadas de disputa judicial, foi somente no ano de 2015 que a comunidade finalmente conseguiu ingressar na área da fazenda, por meio de ato cerimonial e administrativo; cerimonial em virtude da marcha a pé da comunidade, liderada por Toninho, até a sede da fazenda, ocasião em que uma placa, instalada pelo fazendeiro, que proibia o acesso dos membros da comunidade a uma passagem de servidão, foi retirada ao longo do cortejo de ingresso na fazenda, gesto carregado de forte representação simbólica.

Tratou-se também de ato administrativo, em razão de ser ato oficial de cumprimento de decisão judicial favorável ao reconhecimento do território de remanescentes de quilombos na antiga fazenda São José.

A resolução do conflito pela terra não encerrou a trajetória de luta comunitária. Na verdade, tal conjuntura acabou por inaugurar um novo ciclo, que poderá ser marcado tanto pela capacidade de organização interna da comunidade como pela capacidade de estabelecer diálogos institucionais e construção de agendas que visem a assegurar caminhos que promovam o reconhecimento cultural comunitário, bem como a inclusão social, política e econômica dos integrantes do território.

É dentro deste novo ciclo que se pretende, de modo exploratório, examinar os limites e as potencialidades da comunidade de São José da Serra em relação à prática social do turismo, tomando como referencial a perspectiva do turismo de base comunitária.

Vale ressaltar que a comunidade, consciente da força de suas tradições, vem realizando um esforço para dinamizar atividades e práticas sociais que, para além de reforçar sua própria identidade coletiva, indicarão os caminhos para a construção de uma agenda em torno da atividade turística.

Em suma, os esforços empreendidos de modo colaborativo pela comunidade de São José da Serra têm como escopo reforçar as expressões imateriais de sua cultura, como a espiritualidade, a gastronomia e as danças e ritos que, paulatinamente, vão ocupando uma agenda permanente de atividades que ocorrem na comunidade, relacionadas ao turismo - tais como a festa da cultura negra, realizada regularmente no mês de maio; e a queima do balaio, festa de cunho religioso e cerimonial realizada no mês de novembro. 


\subsection{Desafios comunitários e potencialidades culturais para o Turismo de Base Comunitária}

A reflexão proposta neste artigo vale-se de constatações empíricas apoiadas em dois aspectos essenciais: (a) a vitalidade da cultura presente na comunidade, pois ela confere vigor e robustez às suas tradições e práticas cotidianas; (b) o desejo, expresso no art. 4으 do estatuto da Associação da Comunidade Negra Remanescente de Quilombo São José da Serra, de "promover o turismo cultural próprio das suas tradições na região" (MATTOS, 2006, p. 180).

Ressalte-se que o parágrafo quarto do supracitado artigo traz ainda como objetivo "promover o apoio e a execução de formas de associação de bens e trabalho coletivo entre os lavradores, sob o regime comunitário" (MATTOS, 2006, p. 180). Percebe-se, assim, a sensibilidade, ao menos do ponto de vista formal, da comunidade de São José da Serra em valer-se do turismo como estratégia para a promoção de suas tradições culturais, orientado primordialmente por ações coletivas como regime predominante de trabalho e organização.

É forçoso reconhecer que os desafios para a implementação do turismo de base comunitária são grandes. Ao se observar as dinâmicas sociais no interior das comunidades e sua aderência ao sentido do que vem a ser o turismo de base comunitária, não é incomum encontrar as condições apontadas por Mielke e Pegas (2013), que salientam as dificuldades para a difusão de estratégias de turismo comunitário. Assim sendo, os três elementos analisados pelos supracitados autores (quais sejam, dificuldades de acesso ao mercado, problemas de governança interna das comunidades, além de dificuldades no estabelecimento de parcerias estratégicas) mostram-se evidentes na comunidade de São José da Serra, conforme se descreverá nos parágrafos subsequentes.

A comunidade quilombola sob análise no artigo está distante cerca de 50 quilômetros da sede do município de Valença. Para se chegar ao território de São José da Serra, saindo da sede de Valença, faz-se necessário gastar mais de uma hora de ônibus ou carro, passando por estradas sinuosas, inclusive sem asfaltamento adequado (é de cerca de quatro quilômetros o percurso de estrada de terra que liga a rodovia RJ-137 até a sede da comunidade de São José).

Destaque-se, ademais, que não há posto de saúde na comunidade, e o hospital mais próximo, que faz atendimentos básicos de saúde, fica no distrito de Santa Isabel do Rio Preto. Há, no território quilombola por ora analisado, uma escola multisseriada mantida pelo município de Valença para as crianças do ensino fundamental, e os jovens que estão no ensino médio são transportados por coletivos até o distrito de Santa Isabel do Rio Preto, onde há uma escola estadual. Vale registrar que, até meados de 2015, tanto a escola municipal quanto o transporte escolar para os estudantes do ensino médio funcionavam de modo irregular.

Em síntese, pode-se inferir que as dificuldades de acesso perfazem um impeditivo, em muitas circunstâncias, para que os visitantes consigam acessar os produtos turísticos existentes no quilombo de São José da Serra. A precariedade das infraestruturas de saúde e educação oferecidas à comunidade não raro impede uma inserção plena e efetiva das pessoas na lógica do turismo comunitário no território, fazendo com que o oferecimento dos produtos turísticos pela comunidade não seja regular e de qualidade.

No campo das políticas públicas, é ilustrativo que somente no ano de 2017 a prefeitura de Valença passou a contar, por meio da Lei n. 2.998/2017, com a instituição do Conselho Municipal de Políticas de Promoção da Igualdade Racial (COMUPPIR - VA/RJ), vinculado à Secretaria Municipal de Assistência Social. Tal Conselho possui a finalidade precípua de elaborar e imple- 
mentar, em todas as esferas da administração pública do município de Valença, políticas públicas destinadas a garantir igualdade de oportunidade e de direito entre todos, além de assegurar à população o pleno exercício de sua cidadania, visando à igualdade racial.

Entretanto constata-se que não houve, desde sua criação, nenhuma ação efetiva do COMUPPIR - VA/RJ, sendo ainda um entrave ao financiamento de políticas públicas o fato de que a prefeitura municipal possui pendências no CAUC $^{3}$ (Serviço Auxiliar de Informação para Transferências Voluntárias), razão pela qual está impedida de acessar políticas federais, tais como os editais da Secretaria de Políticas de Promoção da Igualdade Racial (SEPPIR), além de não ter acesso a transferências voluntárias enquanto não for saneado o rol das pendências.

Além das circunstâncias gerais, sobretudo de infraestrutura e de acesso a políticas públicas relacionadas anteriormente, e que dizem respeito mais a fatores exógenos, são igualmente relevantes os aspectos internos à comunidade, ou elementos endógenos, como a distribuição de poder e recursos entre os membros da comunidade, assim como a densidade da participação social e a disponibilidade para a construção de iniciativas coletivas.

Observa-se que, para além dos esforços dos habitantes de São José da Serra em organizar-se em torno de ações associativas e solidárias, ainda há uma necessidade de aprimorar a governança interna da comunidade, com destaque para a importância de se reforçar o protagonismo feminino e o juvenil no processo de tomada de decisões. Tal dinâmica, além de captar uma maior diversidade de posições dos indivíduos diante das questões que se impõem à comunidade, também diversifica o acesso ao poder, dando voz a grupos que, atualmente, possuem menor intensidade de participação no processo decisório.

Ainda rememorando o referencial teórico-metodológico sugerido por Mielke e Pegas (2013), faz-se necessário frisar que são evidentes as dificuldades da comunidade de São José da Serra em estabelecer parcerias estratégicas que podem catalisar as iniciativas de turismo de base comunitária no território.

Nesse ínterim, vale destacar que as poucas ações relacionadas ao turismo comunitário que ocorrem em São José da Serra (tais como as festas da cultura negra e da queima do balaio, já destacadas ao longo deste estudo) são materializadas, sobretudo, com base nos esforços e no protagonismo da própria comunidade, sem tipo algum de parceria e/ou agenda regular em torno de políticas públicas que amparem e catalisem esse tipo de ação no território sob análise.

Assim sendo, nota-se que a comunidade em questão está completamente excluída dos circuitos de turismo histórico, cultural e gastronômico que existem no município de Valença e em toda a região sul do Estado do Rio de Janeiro.

Aliás, neste particular, destaque-se que a região sul-fluminense se insere na lógica do chamado "turismo do Vale do Café" ${ }^{4}$, que resgata o aspecto histórico da região em tela, que foi uma importante produtora de café em fins do século XVIII. De todo modo, percebe-se que o turismo atualmente empreendido na região coloca a cultura e história do negro em uma posição absolutamente secundária. As fazendas históricas, por exemplo, que são importantes atrativos turísticos do território, utilizam-se da cultura e história do povo negro de um modo muitas vezes

\footnotetext{
${ }^{3}$ O CAUC, ligado administrativamente à Secretaria do Tesouro Nacional (STN), refere-se a um sistema que registra eventuais pendências dos entes federativos quanto às transferências voluntárias, entendidas como a entrega de recursos correntes ou de capital que não decorra de determinações constitucionais.

${ }^{4}$ Vale lembrar que tal "lógica turística" é referendada e apoiada pelo Ministério do Turismo, por intermédio da política de regionalização e fomento da atividade turística no país.
} 
caricato, "teatralizando" o período da escravidão sem contextualizá-la no âmbito do ciclo do café, negligenciando, portanto, toda a potência, vitalidade e resistência inerente à cultura do negro, de um modo geral, e dos negros remanescentes de quilombos, em particular.

Percebe-se que a própria lógica do turismo na porção sul do Estado do Rio de Janeiro faz com que a comunidade de São José da Serra veja-se excluída das possibilidades de inserir o turismo comunitário como um atrativo do sistema turístico local; turismo comunitário este que seja revestido da vivacidade e potência da cultura, história e modo de vida do povo negro.

Ressalte-se que o foco dado pelo "turismo do Vale do Café" ao circuito de fazendas históricas da região sul-fluminense, enfatizando sobretudo os detalhes do ciclo do café e a participação dos negros enquanto mão de obra escrava nesse período, faz com que outros atributos inerentes à cultura e aos modos de vida da população negra acabem não constituindo os focos do turismo local. Sendo assim, observa-se que, em função disso, as iniciativas de turismo de base comunitária empreendidas em São José da Serra acabam ficando completamente alijadas da lógica "oficial" de promoção do turismo no território de Valença e em toda a região sul do Estado do Rio de Janeiro.

De todo modo, o que nos interessa aqui, aliás, é examinar também, ainda que de modo empírico e exploratório, o potencial social e cultural da comunidade remanescente de São José, pois, se para Mattos (2006, p. 180) o jongo ${ }^{5}$ de São José é elemento central na estratégia de promoção do turismo cultural, sobretudo ao unir tradição e inovação, acrescentamos uma dimensão que é o pilar das tradições do quilombo: a dimensão espiritual, aspecto este que não pode ser invisível à análise, uma vez que sustenta boa parte do conjunto de dinâmicas sociais e práticas materiais e imateriais que traduzem a cultura comunitária.

A espiritualidade presente por meio da umbanda e do sincretismo religioso típico das comunidades coloniais é a base de grande parte das expressões culturais da comunidade de São José da Serra, razão pela qual visitantes e adeptos frequentam a comunidade com certa regularidade. O "terreiro" ou o "centro" carregam a sua espiritualidade para as festividades, como as celebrações da festa da cultura negra, da queima do balaio, bem como para outras manifestações que se revelam nas danças e nos ritmos, como o jongo e o calango ${ }^{6}$, assim como no conhecimento tradicional sobre o uso de plantas medicinais no tratamento de enfermidades.

É neste sentido que se deve ressaltar a importância e o espaço que o sagrado ocupa no cotidiano da comunidade, da sua influência na construção de uma identidade e de uma relação com o território e com a natureza que o integra, com destaque, como já afirmado, para o conhecimento tradicional sobre as plantas medicinais.

Muito embora a sabedoria tradicional sobre as plantas possa sugerir um aspecto prático e fundamental na conservação da saúde da comunidade, o essencial aqui é reconhecer o lugar que o sagrado ocupa na relação cultural da comunidade com o seu território, com a natureza, como bem expressa estudo realizado na comunidade de São José por Rocha (2014, p. 170):

\footnotetext{
${ }^{5}$ O jongo é uma dança ritmada de origem africana, que se utiliza de tambores e de letras improvisadas por ritmistas, remetendo à história e cultura do povo negro. Mais informações podem ser obtidas em Gandra (1995).

${ }^{6} \mathrm{O}$ calango é um ritmo de influência afro-negra, típica na região do Paraíba do Sul paulista e fluminense, em que normalmente dois ou mais ritmistas recitam versos improvisados, que compõem uma história. O calango é dançado normalmente em duplas, de tal modo que as pessoas bailam arrastando os pés. Para mais informações, ver Côrtes (2000).
} 
Esses lugares sagrados são constituídos por áreas assim definidas pela própria história da comunidade, por seus reconhecidos valores ligados à religião ou crenças como sendo lugares de culto, lembrança, afetividade, pertencimento, materialidade, identidade, diversão, limpeza espiritual, entre outros atributos que dão a esses espaços significativos níveis de diversidade biológica e cultural.

Neste sentido, a comunidade conserva em seu território, de modo genuíno, práticas sociais e culturais em que o lugar do sagrado está no centro das relações comunitárias. É evidente constatar que tais práticas conferem uma singularidade ao território, o que guarda relativa aderência com o que sustenta Zaoual (2008, p. 57), ao apontar que a “clientela (turística, por assim dizer) procura verdadeiros sítios que combinam a autenticidade e a profundidade do intercâmbio intercultural, além da harmonia com a natureza e a memória dos lugares".

Mas há ainda um outro aspecto essencial que se pode acrescentar, que é o sentido da experiência que se faz presente e possível de realizar-se no território, possibilidade aberta pelas particularidades que se fazem não somente passíveis de serem materialmente e objetivamente reconhecidas, mas sobretudo pelas possibilidades de serem sentidas, vividas, partilhadas, como aquilo que toca no âmago da existência, da nossa inquietante busca pelo que nos é autêntico e nos remete ao contato com uma origem ancestral, com uma experiência histórica que de fato nos sensibilize ou nos emocione, sobretudo se potencializada pela simplicidade do contato comunitário em que as relações entre os visitantes e os visitados configuram o aspecto central.

Neste sentido, em um texto sobre o significado da experiência, Bondía (2002, p. 21) aponta um caminho de reflexão em que:

A experiência é o que nos passa, o que nos acontece, o que nos toca. Não o que se passa, não o que acontece, ou o que toca. A cada dia se passam muitas coisas, porém, ao mesmo tempo, quase nada nos acontece. Dir-se-ia que tudo o que se passa está organizado para que nada nos aconteça. Walter Benjamin, em um texto célebre, já observava a pobreza de experiências que caracteriza o nosso mundo. Nunca se passaram tantas coisas, mas a experiência é cada vez mais rara.

Se, para Zaoual (2008), a tendência no turismo contemporâneo é ser o lugar do diálogo dos sentidos, o lugar do reconhecimento intercultural e onde são expressas as novas trajetórias e exigências por demandas de serviços turísticos, o sentido da experiência como o apresentado por Bondía (2002) está presente no cotidiano sagrado da comunidade remanescente do quilombo de São José da Serra.

Esta é uma importante virtude da comunidade, a presença de uma dimensão espiritual que também se revela afetiva no acolhimento comunitário e que, ao mesmo tempo, expressa todo um conteúdo de tradições que vão da dança, como o jongo, ao improviso do calango e aos ritmos das percussões; do conhecimento sobre o preparo e emprego das plantas medicinais aos temperos e aromas expressos na gastronomia, na paisagem, envolta por montanhas e trilhas, cachoeiras e açudes, onde se revela a integração da comunidade com a natureza, expressa também nos contatos singulares com os caminhos e as bordas das matas, nas trilhas como as do jequitibá, que atravessam ou conduzem aos locais sagrados e históricos, assim como na particular tradição de conservação das sementes tradicionais de milho ou feijão, preservadas ao longo de gerações, salvaguardando valioso patrimônio genético e assegurando as bases para a segurança alimentar da comunidade. 


\section{CONSIDERAÇÕES FINAIS}

Se as principais inferências e análises realizadas no âmbito do presente artigo sinalizam que há um conjunto expressivo de limites e potencialidades para a implementação de iniciativas de turismo de base comunitária no território do quilombo de São José da Serra, torna-se importante entender como tais limites e possibilidades se apresentam diante das singularidades do contexto social, político e econômico do território da comunidade.

O quadro 1 abaixo sumariza quais são os mais relevantes limites e potencialidades das iniciativas de turismo comunitário no território de São José da Serra, indicando as respectivas consequências de cada um desses limites e potencialidades.

Quadro 1- Limites e potencialidades do turismo comunitário em São José da Serra

\begin{tabular}{|c|c|c|c|}
\hline \multicolumn{2}{|r|}{ Limites } & \multicolumn{2}{|c|}{ Potencialidades } \\
\hline Quais são? & O que geram? & Quais são? & O que geram? \\
\hline $\begin{array}{l}\text { Dificuldades de } \\
\text { acesso à comuni- } \\
\text { dade }\end{array}$ & $\begin{array}{l}\text { Empecilhos para que os tu- } \\
\text { ristas visitem a comunidade, } \\
\text { com efeitos diretos sobre a } \\
\text { taxa de visitação }\end{array}$ & $\begin{array}{l}\text { Reconhecimento do } \\
\text { valor do turismo cul- } \\
\text { tural no estatuto da } \\
\text { associação de mora- } \\
\text { dores da comunidade }\end{array}$ & $\begin{array}{l}\text { Sensibilização da comuni- } \\
\text { dade para a importância } \\
\text { e potência do turismo, ao } \\
\text { menos do ponto de vista } \\
\text { formal }\end{array}$ \\
\hline $\begin{array}{l}\text { Precária infraestru- } \\
\text { tura de provisão de } \\
\text { serviços públicos } \\
\text { de saúde e educa- } \\
\text { ção à comunidade }\end{array}$ & $\begin{array}{l}\text { Dificuldades para estabelecer } \\
\text { maior engajamento comu- } \\
\text { nitário e para reconhecer a } \\
\text { importância do turismo como } \\
\text { fonte de renda e trabalho }\end{array}$ & $\begin{array}{l}\text { Atividades culturais } \\
\text { que envolvem danças, } \\
\text { ritos e artesanatos }\end{array}$ & $\begin{array}{l}\text { Produtos turísticos comu- } \\
\text { nitários, renda e trabalho, } \\
\text { além da valorização da cul- } \\
\text { tura da comunidade }\end{array}$ \\
\hline $\begin{array}{l}\text { COMUPPIR - VA/RJ } \\
\text { inoperante }\end{array}$ & $\begin{array}{l}\text { Escassez de políticas públicas } \\
\text { e ações voltadas à instalação } \\
\text { de infraestruturas, bem como } \\
\text { limites no acesso a financia- } \\
\text { mento público e ausência de } \\
\text { estratégias institucionais de } \\
\text { valorização da cultura, das } \\
\text { tradições e do modo de vida } \\
\text { da comunidade }\end{array}$ & $\begin{array}{l}\text { Espiritualidade ine- } \\
\text { rente à comunidade }\end{array}$ & $\begin{array}{l}\text { Coesão social e eventuais } \\
\text { produtos turísticos comuni- } \\
\text { tários, de cunho cultural e/ } \\
\text { ou religioso }\end{array}$ \\
\hline $\begin{array}{l}\text { Pendências legais e } \\
\text { jurídicas da prefei- } \\
\text { tura municipal }\end{array}$ & $\begin{array}{l}\text { Impossibilidade de acessar } \\
\text { recursos financeiros via trans- } \\
\text { ferências voluntárias }\end{array}$ & $\begin{array}{c}\text { Conhecimento tradi- } \\
\text { cional sobre o preparo } \\
\text { e uso das plantas me- } \\
\text { dicinais }\end{array}$ & $\begin{array}{l}\text { Produtos turísticos comuni- } \\
\text { tários, de cunho cultural }\end{array}$ \\
\hline $\begin{array}{l}\text { Governança co- } \\
\text { munitária com } \\
\text { limitada partici- } \\
\text { pação de jovens e } \\
\text { mulheres }\end{array}$ & $\begin{array}{l}\text { Dificuldades para o estabe- } \\
\text { lecimento de ações coletivas } \\
\text { na comunidade com maior } \\
\text { protagonismo feminino e de } \\
\text { jovens }\end{array}$ & $\begin{array}{l}\text { Possibilidade de os } \\
\text { turistas partilharem } \\
\text { experiências autênti- } \\
\text { cas e transformadoras }\end{array}$ & $\begin{array}{l}\text { Coesão social, valorização } \\
\text { da cultura e do território, } \\
\text { além de as experiências au- } \\
\text { tênticas constituírem produ- } \\
\text { tos turísticos comunitários }\end{array}$ \\
\hline $\begin{array}{c}\text { Indiferença quanto } \\
\text { ao potencial tu- } \\
\text { rístico da comuni- } \\
\text { dade }\end{array}$ & $\begin{array}{c}\text { Fraca adesão comunitária às } \\
\text { iniciativas de promoção do } \\
\text { turismo }\end{array}$ & Gastronomia & $\begin{array}{c}\text { Valorização da cultura, } \\
\text { geração de renda e tra- } \\
\text { balho, além de constituir } \\
\text { produto turístico de caráter } \\
\text { comunitário }\end{array}$ \\
\hline $\begin{array}{l}\text { Lógica do "turismo } \\
\text { do vale do café" no } \\
\text { sul fluminense }\end{array}$ & $\begin{array}{l}\text { Dificuldades para que a co- } \\
\text { munidade se insira no turismo } \\
\text { regional e para articulação } \\
\text { com parceiros estratégicos }\end{array}$ & $\begin{array}{l}\text { Paisagens e beleza do } \\
\text { território }\end{array}$ & $\begin{array}{l}\text { Valorização do território e de } \\
\text { sua cultura, além de consti- } \\
\text { tuir produto turístico comu- } \\
\text { nitário por meio, sobretudo, } \\
\text { de percursos em trilhas e } \\
\text { banhos de cachoeiras }\end{array}$ \\
\hline
\end{tabular}

Fonte: Elaborado pelos autores, a partir dos dados da pesquisa empírica. 
De uma maneira geral, entende-se que o enfrentamento dos limites para a difusão das estratégias de turismo comunitário em São José da Serra exige ações de cunho exógeno e endógeno à comunidade.

As ações exógenas envolvem uma sensibilização, principalmente por parte do poder público local e regional, para que: (a) haja uma melhora da infraestrutura de acesso, de saúde e de educação oferecidas à comunidade; (b) se viabilize uma atuação efetiva por parte do COMUPPIR - VA/RJ, viabilizando políticas públicas e ações institucionais que fortaleçam a identidade e cultura do povo de São José da Serra; (c) se equacionem as pendências legais do município, viabilizando o acesso, por parte da comunidade, a recursos financeiros decorrentes de transferências voluntárias; e (d) se reconheça, efetivamente, o turismo comunitário praticado em São José da Serra como um relevante e rico produto do turismo local e regional.

Deve-se destacar que é fundamental o estabelecimento de um conjunto de ações endógenas para que se enfrentem os limites ao turismo comunitário em São José da Serra. Essas ações endógenas passam pelo fortalecimento do senso de comunidade do povo do território analisado, principalmente para que: (a) se exijam ações, por parte do poder público, que beneficiem a comunidade e fortaleçam a geração de ocupação e renda, não raro por intermédio do turismo comunitário e; (b) se instituam estratégias destinadas a ampliar a participação e a mobilização da comunidade em torno de ações coletivas, sobretudo as que se relacionam com as práticas sociais do turismo comunitário, de modo que tal atividade se desenvolva numa perspectiva colaborativa e solidária, em consonância com os valores culturais e sociais da comunidade.

Verifica-se que as potencialidades para que sejam catalisadas as ações de turismo comunitário no território de São José da Serra são muitas. É preciso que se reconheçam essas potencialidades como o grande trunfo da comunidade, como aspectos que devem vir à tona para que os turistas sejam atraídos à comunidade.

Assim, se tais potencialidades e limites são o produto das dinâmicas socioculturais da comunidade remanescente do quilombo de São José da Serra, julga-se que serão também tais potencialidades e limites os parâmetros sobre os quais a comunidade deverá se debruçar para construir uma nova trajetória, com base no turismo de base comunitária.

Nesse ínterim, acredita-se que as dinâmicas do turismo comunitário em São José da Serra poderão ser propulsores dos processos de inclusão social, econômica e política dos habitantes do território, com capacidade para gerar renda e trabalho, de tal modo que a tomada de decisões e a distribuição equitativa dos benefícios sejam partilhadas pelo maior número de membros da comunidade quanto for possível.

\section{REFERÊNCIAS}

ARAÚJO, Guilherme; GELBCKE, Daniele Lima. Turismo comunitário: uma perspectiva ética e educativa de desenvolvimento. Revista Turismo Visão e Ação, Itajaí, SC, v. 10, n. 3, p. 357-78, set./dez. 2008.

ARRUDA, Dyego de Oliveira; MARIANI, Milton Pasquotto; FISCHER, Rosa Maria. Economia solidária, turismo e desenvolvimento local: algumas reflexões aplicadas ao contexto de Corumbá, Mato Grosso do Sul. In: THOMAZ, Rosângela Custódio; MARIANI, Milton Pasquotto; MORETTI, Edvaldo Cesar; ARRUDA, Dyego de Oliveira (Org.). Turismo, políticas e dinâmicas no espaço rural. Campo Grande: Ed. UFMS, 2013 p. 183-208.

BARDIN, Laurence. Análise de conteúdo. São Paulo: Edições 70, 2011. 
BARTHOLO, Roberto. Sobre o sentido da proximidade: implicações para um turismo situado de base comunitária. In: BARTHOLO, Roberto; SANSOLO, Davis Gruber; BURSZTYN, Ivan (Org.). Turismo de Base Comunitária: diversidade de olhares e experiências brasileiras. Rio de Janeiro: Letra e Imagem, 2009. p. 45-54.

BISPO, Marcelo de Souza; GODOY, Arilda Schmidt. A etnometodologia enquanto caminho teóricometodológico para investigação da aprendizagem nas organizações. Revista de Administração Contemporânea, Rio de Janeiro, v. 16, n. 5, p. 684-704, set./out. 2012.

BONDÍA, Jorge Larrosa. Notas sobre a experiência e o saber de experiência. Revista Brasileira de Educação, Rio de Janeiro, n. 19, p. 20-8, jan./abr. 2002.

BRASIL. Dinâmica e diversidade do turismo de base comunitária: desafio para a formulação de política pública. Brasília, DF: Ministério do Turismo, 2010. 88 p. (Relatório Técnico).

BRASIL. Constituição da República Federativa do Brasil (1988). Brasília, DF: Senado Federal, 1988. 292 p.

BURGOS, Andrés; MERTENS, Frédéric. As redes de colaboração no turismo de base comunitária: implicações para a gestão participativa. Tourism \& Management Studies, Faro, Portugal, v. 12, n. 2, p. 18-27, 2016.

BURGOS, Andrés; MERTENS, Frédéric. A perspectiva relacional na gestão do turismo de base comunitária: o caso da Prainha do Canto Verde. Caderno Virtual de Turismo, Rio de Janeiro, v. 15, n. 1, p. 81-98, abr. 2015.

CORIOLANO, Luzia Neide; VASCONCELOS, Fábio Perdigão. Região, desenvolvimento regional e turismo comunitário. Revista Brasileira de Desenvolvimento Regional, Blumenau, v. 1, n. 1, p. 95-111, 2013.

CÔRTES, Gustavo Pereira. Dança, Brasil! Festas de danças populares. Belo Horizonte:. Leitura, 2000.

FABRINO, Nathalia Hallack; NASCIMENTO, Elimar Pinheiro do; COSTA, Helena Araújo. Turismo de Base Comunitária: uma reflexão sobre seus conceitos e práticas. Caderno Virtual de Turismo, Rio de Janeiro, v. 16, n. 3, p. 172-90, dez. 2016.

GANDRA, Edir. Jongo da Serrinha: do terreiro aos palcos. Rio de Janeiro: Giorgio Gráfica e Editora, 1995.

GARFINKEL, Harold. Studies in ethnomethodology. New Jersey: Prentice-Hall, 1967.

GODOY, Arilda Schmidt. Introdução à pesquisa qualitativa e suas possibilidades. Revista de Administração de Empresas, São Paulo, v. 35, n. 2, p. 57-63, mar./abr. 1995.

GRIMM, Isabel Jurema; SAMPAIO, Carlos Alberto Cioce. Turismo comunitário: possibilidade de adaptação diante das mudanças ambientais e climáticas. Caderno Virtual de Turismo, Rio de Janeiro, v. 16, n. 2, p. 62-78, ago. 2016.

GUZATTI, Thaise Costa; SAMPAIO, Carlos Alberto Cioce; CORIOLANO, Luzia Neide Menezes Teixeira. Turismo de base comunitária em territórios rurais: caso da Associação de Agroturismo Acolhida na Colônia (SC). Revista Brasileira de Ecoturismo, Diadema, SP, v. 6, n. 1, p. 93-106, jan./abr. 2013.

IRVING, Marta de Azevedo. Reinventando a reflexão sobre turismo de base comunitária: inovar é possível? In: BARTHOLO, Roberto; SANSOLO, Davis Gruber; BURSZTYN, Ivan (Org.). Turismo de Base Comunitária: diversidade de olhares e experiências brasileiras. Rio de Janeiro: Letra e Imagem, 2009. p. 108-21.

LACERDA, Liliane; ALBUQUERQUE, Lidiamar Barbosa de; MILANO, Sinéia Mara Zattoni; BRAMBILLA, Márcia. Agroindustrialização de alimentos nos assentamentos rurais do entorno do Parque Nacional da 
Serra da Bodoquena e sua inserção no mercado turístico, Bonito/MS. Interações - Revista Internacional de Desenvolvimento Local, Campo Grande, MS, v. 8, n. 1, p. 55-64, mar. 2007.

LIMA, Robson Pereira de. Turismo de base comunitária como inovação social. 2011. 191f. Tese (Doutorado em Engenharia de Produção) - Universidade Federal do Rio de Janeiro (UFRJ), Rio de Janeiro, 2011.

LUSTOSA, Isis Maria Cunha; ALMEIDA, Maria Geralda de. Os territórios emergentes de turismo e as redes de turismo comunitário: o caso da Terra Indígena 'Lagoa Encantada' do povo Jenipapo-Kanindé, Ceará, Brasil. Pasos - Revista de Turismo y Patrimonio Cultural, El Sauzal (Tenerife), Espanha, v. 9, n. 3, p. 95-104, maio 2011.

MANO, Apoena Dias; MAYER, Verônica Feder; FRATUCCI, Aguinaldo Cesar. Community-based Tourism in Santa Marta Favela/RJ: social, economic and cultural opportunities. Revista Brasileira de Pesquisa em Turismo, São Paulo, v. 11, n. 3, p. 413-35, set./dez. 2017.

MATTOS, Hebe Maria. Políticas de reparação e identidade coletiva no meio rural: Antônio Nascimento Fernandes e o quilombo São José. Revista Estudos Históricos, Rio de Janeiro, v. 1, n. 37, p. 167-89, jan./ jun. 2006.

MAXWELL, Joseph. Qualitative research design: an interactive approach. 3. ed. New York: Sage Publications, 2012.

MAYNARD, Douglas; CLAYMAN, Steven. The diversity of ethnomethodology. Annual Review of Sociology, v. 17, n. 1, p. 385-418, 1991.

MIELKE, Eduardo Jorge Costa. Desenvolvimento Turístico de Base Comunitária. Campinas, SP: Átomo \& Alínea, 2010.

MIELKE, Eduardo Jorge Costa; PEGAS, Fernanda Vasconcellos. Turismo de base comunitária no Brasil. Insustentabilidade é uma questão de gestão. Revista Turismo em Análise, São Paulo, v. 24, n. 1, p. 17089, abr. 2013.

NUNES, Mirelle Barcos; MENEZES, Magali Mendes de. Turismo de Base Comunitária: a reconstrução de identidades desde a experiência do encontro. Revista Cenário, Brasília, v. 5, n. 9, p. 97-108, dez. 2017.

OLIVEIRA, Samir Adamoglu de; MONTENEGRO, Ludmilla Meyer. Etnometodologia: desvelando a alquimia da vivência cotidiana. Cadernos EBAPE.BR, Rio de Janeiro, v. 10, n. 1, p. 129-45, mar. 2012.

ROCHA, Joyce Alves. Quilombo São José da Serra: o etnoconhecimento na perspectiva socioambiental. 2014. 353 f. Tese (Doutorado em Meio Ambiente) - Universidade do Estado do Rio de Janeiro (UERJ), Rio de Janeiro, 2014.

SALAZAR, Noel. Community-based cultural tourism: issues, threats and opportunities. Journal of Sustainable Tourism, v. 20, n. 1, p. 9-22, jan. 2012.

SANCHO, Altair; MALTA, Guilherme. Pesquisa de Demanda para Turismo de Base Comunitária: desafios à promoção do encontro entre comunidades e viajantes. Revista Turismo em Análise, São Paulo, v. 26, n. 1, p. 38-67, 2015.

SILVA, Francisca de Paula Santos da; MATTA, Alfredo Eurico Rodrigues; SÁ, Natália Silva Coimbra de. Turismo de base comunitária no antigo Quilombo Cabula. Caderno Virtual de Turismo, Rio de Janeiro, v. 16, n. 2, p. 79-92, ago. 2016. 
SILVA, Gustavo Augusto Fonseca. Comunidade Quilombola São José da Serra. Rio de Janeiro. Belo Horizonte: FAFICH e INCRA, 2016. (Coleção Terra de Quilombos).

SILVA, Rosijane Evangelista da. O turismo comunitário como ferramenta de desenvolvimento local nos territórios quilombolas. Revista Brasileira de Ecoturismo, Diadema, SP, v. 7, n. 1, p. 178-97, fev./abr. 2014.

TOLKACH, Denis; KING, Brian. Strengthening Community-Based Tourism in a new resource-based island nation: Why and how? Tourism Management, v. 48, p. 386-98, 2015.

ZAOUAL, Hassan. Do turismo de massa ao turismo situado: quais as transições? Caderno Virtual de Turismo, Rio de Janeiro, v. 8, n. 2, p. 1-14, 2008.

\section{Sobre os autores:}

Dyego de Oliveira Arruda: Doutor em Administração de Organizações pela Universidade de São Paulo (USP). É professor do quadro permanente do Centro Federal de Educação Tecnológica Celso Suckow da Fonseca (CEFET/RJ), lecionando em cursos de graduação e no Programa de Pós-Graduação (nível mestrado acadêmico) em Relações Étnico-Raciais da instituição. Tem interesse e experiências nas seguintes áreas de pesquisa: economia do turismo, políticas públicas, ações afirmativas e desenvolvimento local/regional. E-mail: dyego.arruda@gmail.com, Orcid: http://orcid.org/0000-0002-9514-284X

Juliano Pessanha Gonçalves: Mestre em Administração Pública pela Escola Brasileira de Administração Pública da Fundação Getulio Vargas (EBAP/FGV). É professor do quadro permanente, em regime de dedicação exclusiva, do Centro Federal de Educação Tecnológica Celso Suckow da Fonseca (CEFET/RJ), lecionando em cursos de graduação da instituição. Possui experiência e interesse nas seguintes áreas: políticas públicas, turismo de base comunitária e desenvolvimento local/regional. E-mail: jpg.sagres@gmail.com, Orcid: https://orcid.org/0000-0003-1584-2270 
